\title{
An Adherent Subline of a Unique Small-Cell Lung Cancer Cell Line Downregulates Antigens of the Neural Cell Adhesion Molecule
}

\author{
L. Austin Doyle, Michael Borges, Arif Hussain, Anthony Elias, ${ }^{\star}$ and Takafumi Tomiyasu \\ University of Maryland Cancer Center and Department of Medicine, University of Maryland School of Medicine, \\ Baltimore, Maryland 21201; and *Dana Farber Cancer Institute, Boston, Massachusetts 02115
}

\begin{abstract}
Small-cell lung cancer (SCLC) lines are distinguished from non-small-cell lung cancer (NSCLC) lines by their growth in floating aggregates, in contrast to the adherent monolayers formed by NSCLC cells in culture. Of 50 well-characterized SCLC lines recently described by the National Cancer Institute (NCI)-Navy Medical Oncology Branch, only four variant cell lines (SCLC-v) grew as adherent monolayers. One line, NCI-H446, was unique in growing long-term with coexisting floating and surface adherent subpopulations. We have physically segregated these two populations over many passages in vitro to enrich for relatively pure cultures of floating and adherent cells. No differences in c-myc expression, keratin pattern, or cytogenetic appearance were found between the adherent and floating sublines. However, expression of the neuroendocrine marker neuron-specific enolase in the floating cells was three times that found in the adherent cells. The floating subline also had much greater surface expression of neuroendocrine tumor antigens detected by monoclonal antibodies UJ13A and HNK-1, which have been recently shown to detect the neural cell adhesion molecule (NCAM) on SCLC cells. Two other adherent SCLC-v lines were also found to be unreactive with UJ13A and HNK-1, generalizing the association between NCAM expression and the growth of most SCLC cultures as floating aggregates. In conclusion, we have an interesting model to study expression of NCAM as related to the adhesive properties of SCLC cells. (J. Clin. Invest. 1990. 86:1848-1854.) Key words: lung cancer • neural cell adhesion molecule • neuron-specific enolase
\end{abstract}

\section{Introduction}

A striking difference between small-cell lung cancer (SCLC) ${ }^{1}$ and non-small-cell lung cancer (NSCLC) cells in vitro is that

Part of this work has appeared as an abstract (1987. Proc. Am. Assoc. Cancer Res. 28:124).

Mr. Tomiyasu's present address is Hayashibara Fujisaki Cell Center, 675-1 Fujisaki, Okayama, 702 Japan.

Address reprint requests to Dr. Doyle, University of Maryland Cancer Center, 22 South Greene Street, Baltimore, MD 21201.

Received for publication 2 November 1989 and in revised form 2 July 1990.

1. Abbreviations used in this paper: NCAM, neural cell adhesion molecule; NCI, National Cancer Institute; NSCLC, non-small-cell lung cancer; NSE, neuron-specific enolase; SCLC and SCLC-v, small-cell lung cancer and variant SCLC; SC-1, SCLC cluster 1.

J. Clin. Invest.

(C) The American Society for Clinical Investigation, Inc 0021-9738/90/12/1848/07 \$2.00

Volume 86, December 1990, 1848-1854
SCLC cells generally float in spheroid aggregates and NSCLC cells grow as adherent monolayers (1). Classic SCLC cells tend to grow in tight spheroids with central necrosis whereas variant SCLC cells (SCLC-v) grow in looser branching chains (2). A small number of SCLC-v lines have been noted to grow in adherent monolayers in vitro (3). These adherent variant cells, referred to as having type 4 morphology, are clearly SCLC by other morphologic, cytogenetic, and biochemical features. In the experience of the National Cancer Institute (NCI)-Navy Medical Oncology Branch, only one well-characterized line has been described as growing with coexisting adherent and floating subpopulations, although similar lines have been described in the literature (3). This line, NCI-H446, was derived from the pleural effusion of a SCLC patient and expresses the SCLC biochemical markers neuron-specific enolase (NSE) and the brain isoenzyme of creatine kinase $(4,5)$. NCI-H446 cells form tumors with SCLC-v morphology (3), when implanted in nude mice.

The adherent NCI-H446 cells, although distinct from NSCLC cells by electron microscopy, mimic the culture properties of NSCLC (3). We were interested in whether the adherent SCLC cells had lost any of the neuroendocrine or immunologic markers distinguishing SCLC from NSCLC. By developing floating and surface adherent sublines of the NCI-H446 line, we were able to directly examine the association of growth as an adherent monolayer on several characteristic amine precursor uptake and decarboxylation or neuroendocrine properties of SCLC cells.

Moolenaar et al. (6) and Kibbelaar et al. (7) have recently demonstrated that a dominant surface antigen of SCLC cells, recognized by numerous monoclonal antibodies (MAbs) and termed SCLC cluster 1 (SC-1), is actually a neural cell adhesion molecule (NCAM)-related sialoglycoprotein. We have been able to use our adherent and floating sublines of $\mathrm{H} 446$ to examine expression of NCAM determinants as related to the adherent properties of SCLC cells.

\section{Methods}

Cell cultures. We used the previously described human SCLC-v cell line NCI-H446, derived from the pleural effusion of a patient who had relapsed with disease after treatment with combination chemotherapy (3). Like most SCLC-v lines, H446 cells do not express L-dopa decarboxylase or bombesin-like immunoreactivity (8). The classic SCLC lines H209 and H146, the SCLC-v line N417 and the NSCLC lines $\mathrm{H} 157, \mathrm{H} 125$, and $\mathrm{H} 522$ were used for comparative studies and have been previously described (9). Two unusual SCLC lines, H1607 and H196-B, which form adherent monolayers in vitro, were also used. These two cell lines, characterized as having type 4 SCLC morphology, were derived from patients with SCLC histology (3). H196-B has been further characterized, and forms typical SCLC tumors of an intermediate type when inoculated into nude mice, as well as having detectable SCLC markers of NSE and creatine kinase (3). All cell lines were tested and found to be free of Mycoplasma contamination. 
Culture conditions and experimental protocols were as previously described (3). NSCLC cells were maintained in RPMI-1640 in the presence of $10 \%$ fetal bovine serum and $2 \mathrm{mM}$ L-glutamine. The SCLC cells were grown in $2 \%$ fetal bovine serum with the addition of hydrocortisone, insulin, transferrin, estradiol, and selenium reagents as previously described (10). RPMI-1640 medium and glutamine were from Grand Island Biological Co., Grand Island, NY; the serum from $\mathrm{Hy}$ clone Laboratories, Logan, UT; the insulin, transferrin, and sodium selenite from Collaborative Research Inc., Lexington, MA; and the 17-B-estradiol and hydrocortisone from Sigma Chemical Co., St. Louis, MO.

Creation of floating and adherent subpopulations of NCI-H446. Stable populations of floating $\mathrm{H} 446$ cells were created by serially removing the nonadherent cells to new flasks. Loosely adherent cells were then removed from the original flask by trituration and the most adherent cells were kept. Similar measures over some 40 passages created relatively pure populations of floating and sticking cells which were stable for months in culture. Subcloning of floating and adherent cells used for subsequent assays was performed by selecting single colonies from clonogenic assays.

Calculation of generation time. Approximately $2 \times 10^{5}$ cells were seeded into $25-\mathrm{cm}^{2}$ flasks and viable cells were counted daily for $8 \mathrm{~d}$. Cell counts were performed on a hemocytometer with trypan blue to determine viability. The logarithmic portion of the growth curve was used to calculate the generation time.

Clonogenic assays. Clonogenic assays were performed as described by Carney et al. (11). Briefly, cell pellets were resuspended in $0.4 \mathrm{ml}$ RPMI 1640 with $10 \%$ FBS and were triturated. This suspension was mixed with $3.6 \mathrm{ml}$ of a $0.3 \%$ agarose solution (Difco Laboratories, Inc., Detroit, MI) and 1-ml fractions were plated onto a bottom layer of $0.5 \%$ agarose in 35-mm Petri dishes (Falcon Labware, Oxnard, CA). Total colonies per plate were counted manually after $14 \mathrm{~d}$.

MAbs. HNK-1 reacts with the Leu-7 determinant found on neural tissues, neuroblastoma cells, natural killer cells, and most SCLC but not NSCLC cells (12). HNK-1 has been shown to react with NCAM (13). W6/32 reacts with the HLA-A,B,C heavy chain and BBM.1 reacts with $\beta_{2}$-microglobulin (14). These three MAbs antibodies were obtained from the American Type Culture Collection, Rockville, MD. A rabbit antisera (Dako Corp., Santa Barbara, CA) specific for human $\beta_{2}$-microglobulin was also used. Antibodies AE-1, AE-2, and AE-3 were obtained from Dr. Tien-Treen Sun, New York University School of Medicine. AE-1 reacts against most acidic keratins and AE-3 reacts with all eight of the basic keratin species (15). AE-2 reacts with a 56,000-mol wt acidic keratin and 65,000- and 68,000 mol wt basic keratin species (15). Murine IgG1 MAbs UJ13A and AUA1 are reactive with SCLC cluster antigens 1 and 2, respectively, and were obtained from Dr. Robert Souhami, Courtauld Institute of Biochemistry, London, England (16). The cluster 1 antigen has been determined to be NCAM (6). Melanoma tumors and cell lines are only weakly stained by the cluster 2 antibody AUAl and neuroblastoma is negative, but carcinoid tumors and cell lines are positive, showing, like SCLC, a mixture of neural and epithelial markers (16). A cDNA corresponding to this protein has been recently cloned and sequenced, revealing a transmembrane domain and several potential $N$-glycosylation sites (17). Murine IgG MAbs SWA22 and SWA20 react with SCLC cluster antigens 4 and 5 , respectively, and were provided by Dr. Robert Waibel, University Hospital, Zurich, Switzerland (18).

Radioimmunoassay. The radiobinding assays were performed in 96-well polyvinyl-chloride microtiter plates (Costar Data Packaging, Cambridge, MA) as previously described (9). Adherent cells were harvested by scraping and single-cell suspensions were made by trituration through a 21 -gauge needle. Target cells were fixed at a density of $10^{5}$ cells per well with $0.25 \%$ glutaraldehyde and nonspecific protein binding to the wells was blocked with $1 \%$ bovine serum albumin in PBS. The plates were incubated with $5 \mu \mathrm{g} / \mathrm{ml}$ concentrations of primary antibody for $1 \mathrm{~h}$, followed by incubation with a 1:100 dilution of affinity-purified rabbit anti-mouse Ig hyperimmune serum for $1 \mathrm{~h}$ (Jackson Research Laboratories, Bar Harbor, ME). All incubations were in PBS at room temperature. The detecting reagent was 40,000 cpm/25 $\mu$ l of ${ }^{125}$ I-labeled protein A (New England Nuclear, Boston, MA). Purified mouse myeloma IgG2a (RPC5, Litton Bionetics, Inc., Kensington, MD) was used as a negative control. Counting was performed on a Gamma 4000 counter (Beckman Instruments, Inc., Palo Alto, CA).

Analysis of indirect immunofluorescence by flow cytometry. Adherent cells were harvested by scraping and single-cell suspensions were made by trituration through a 21-gauge needle. After PBS washings, log-phase cultures of SCLC were incubated under saturation conditions with 1:100 to 1:500 dilutions of the protein A purified $(2 \mathrm{mg} / \mathrm{ml})$ antibodies. The total reaction volume was $0.2 \mathrm{ml}$. After incubation with shaking at room temperature for $1 \mathrm{~h}$, the cells were pelleted at $1,500 \mathrm{~g}$, washed with PBS, and incubated for $30 \mathrm{~min}$ with a 1:25 dilution of a fluorescein-conjugated goat anti-mouse IgG (BectonDickinson, Mountain View, CA). The cells were pelleted again, washed in PBS, resuspended in $0.2 \mathrm{ml}$ PBS, and screened through a $43-\mu \mathrm{m}$ wire mesh. The cells were then immediately assayed for mean fluorescence in a FACStar flow cytometer (Becton-Dickinson). $2.5 \times$ $10^{4}$ cells were analyzed using a live gate placed on forward light scatter to exclude cell debris and dead cells. $300 \mathrm{MW}$ of laser power and 488-nm excitation light were used. Fluorescence emission was collected through a 530/30 filter. Percent positive cells and mean fluorescence were determined using the Consort 40 software package (Becton-Dickinson). The lines were also analyzed using a control irrelevant antibody, the murine IgG2a myeloma protein RPC5 or the murine IgG1 myeloma protein MOPC 21.

Preparation and hybridization of lung cancer cell line RNA. Total RNA was prepared from fresh cell cultures by the guanidium isothiocyanate/cesium chloride technique (19), and quantitated by absorbance at $260 \mathrm{~nm}$. Quantitation was confirmed by electrophoretically fractionating a sample on formaldehyde agarose gels, staining with ethidium bromide, and observing the intensities of the ribosomal RNA bands. $20 \mu \mathrm{g}$ of total RNA from each line was denatured and electrophoresed on a $1 \%$ agarose-formaldehyde gel (20) that had been modified by using $2.2 \mathrm{M}$ formaldehyde in the gel and electrophoresing at 70 $\mathrm{V}$ for $5 \mathrm{~h}$. The gels were transferred to nitrocellulose by capillary blotting and hybridization was performed using $50 \%$ formamide with the ${ }^{32} \mathrm{P}$-labeled probe and washing at $65^{\circ} \mathrm{C}$. The c-myc probe consisted of a 1.5-kb ClaI-EcoRI fragment encompassing the third exon of the c-myc gene (21). The c-myc-containing plasmid, PMC 41 3RC, was obtained from Dr. S. Tronick (22). The purified fragment was ${ }^{32} \mathrm{P}$-labeled by random priming (23).

Cytokeratin extraction, electrophoresis, and Western blotting. Cytokeratins were extracted using a procedure modified from $\mathrm{Wu}$ and Rheinwald (24). Cells were washed in PBS, pH 7.4, and placed into a Wheaton hand homogenizer containing $5 \mathrm{ml}$ of $20 \mathrm{mM}$ Tris- $\mathrm{HCl}, \mathrm{pH}$ 7.4, $0.6 \mathrm{M} \mathrm{KCl}, 1 \%$ Triton $\mathrm{X}-100$, and the protease inhibitors $1 \mathrm{mM}$ PMSF, $1 \mathrm{mM}$ EGTA, and $1 \mathrm{mM}$ EDTA at $4^{\circ} \mathrm{C}$. The insoluble fraction was pelleted by centrifugation at $10,000 \mathrm{~g}$ for $15 \mathrm{~min}$, resuspended in the same buffer, recentrifuged, and resuspended in PBS. Gel electrophoresis and Western blotting of cytokeratins were as previously described (25). Each lane contained the high-salt extract from $2 \times 10^{6}$ cells. Briefly, the blots were incubated with either AE-1, AE-2 or AE-3 primary antibodies in 3\% normal goat serum (AE-1 or AE-3, 1:200; $\mathrm{AE}-2,1: 100$ ) for $16 \mathrm{~h}$ at $4^{\circ} \mathrm{C}$. After washing, peroxidase-conjugated rabbit anti-mouse Ig (Cappel) was added, followed by 3-3-diaminobenzidine hydrochloride (Sigma Chemical Co.) $1 \mathrm{mg} / \mathrm{ml}$ with $0.05 \%$ $\mathrm{H}_{2} \mathrm{O}_{2}$ to develop the peroxidase reaction for 3-5 min before quenching with water.

Cytogenetic analysis. Cells were exposed to colcemid at a final concentration of $0.03 \mu \mathrm{g} / \mathrm{ml}$ for $30 \mathrm{~min}$ while the cells were in a logarithmic growth phase. Cells growing in a monolayer were washed briefly twice with HBSS (Grand Island Biological Co.) and exposed to 0.25\% trypsin-EDTA (Grand Island Biological Co.) for 2-3 min. All cells were spun down at $1,200 \mathrm{~g}$ for $5 \mathrm{~min}$. Hypotonic swelling, fixation, chromosome preparation, and Quinicrine banding procedures were the same as previously described (26).

NSE assay. Cell pellets were homogenized in $10 \mathrm{vol}$ of $10 \mathrm{mM}$ Tris phosphate buffer containing $1 \mathrm{mM} \mathrm{MgSO}_{4}$. The homogenate was cen- 
trifuged and the soluble protein concentration of the supernatant was measured by the method of Lowry et al. (27). The NSE assay was performed using a competitive radioimmunoassay protocol as previously described (4).

Statistical analysis. The significance of differences noted between groups of cell lines by various assays was analyzed using a KruskalWallis test.

\section{Results}

Growth characteristics and appearance of cells. The surfaceadherent and floating subpopulations of $\mathrm{H} 446$ cells were successfully segregated into relatively pure populations with a progressively decreasing tendency to revert to the original mixed pattern of growth. The surface-adherent and floating subcultures were maintained in culture for $>18 \mathrm{mo}$ (Fig. 1). The surface-adherent subline initially grew slowly, but became progressively more vigorous and fibroblastoid in appearance. The floating subline had a generation time of $42 \pm 4 \mathrm{~h}$ (SEM of duplicate cultures) and the surface-adherent subline had a generation time of $33 \pm 3 \mathrm{~h}$. Each of the sublines cloned in soft agar with an approximate efficiency of $0.1 \%$ and these colonies were used to clone the sublines.

Expression of NSE. The floating aggregate $\mathrm{H} 446$ cells consistently had higher expression of NSE than did the surfaceadherent $\mathrm{H} 446$ subline. When standardized for protein concentration, the $\mathrm{H} 446$ floating cells, in a representative assay, had $1,021 \mathrm{ng}$ of NSE/mg of protein $\pm 48 \mathrm{ng} / \mathrm{ml}$ (SEM of quadruplicate cultures), compared with $379 \mathrm{ng}$ of NSE/mg of protein $\pm 19 \mathrm{ng} / \mathrm{ml}$ in the surface adherent $\mathrm{H} 446$ subline and $41 \mathrm{ng}$ of $\mathrm{NSE} / \mathrm{mg}$ protein $\pm 8 \mathrm{ng} / \mathrm{ml}$ in a NSCLC line NCI H522. The difference in NSE between the floating aggregate and surfaceadherent $\mathrm{H} 446$ sublines was significant with $P<0.025$.

Cytogenetic analysis. Metaphase chromosomes from between 10 and 13 cells were analyzed for the floating, surfaceadherent, and parent $\mathrm{H} 446$ cell lines. The distribution of chromosome number was virtually the same between the three groups. All three cell lines had the derivative chromosome no. 3 with a deletion in the short arm which overlaps the characteristic deletion of $3 p$ seen in SCLC cells (28). Structural chromosome abnormalities found in common between floating, adherent, and parent lines included $\operatorname{der}(3), \operatorname{del}(8)(\mathrm{p} 21)$, $\operatorname{del}(11)(\mathrm{q} 13), \operatorname{der}(18)+(18 ; ?)(18 \mathrm{pter} \rightarrow 18 \mathrm{q} 23:: ?)$, and del(21)(q22). Numerical chromosomal abnormalities linking
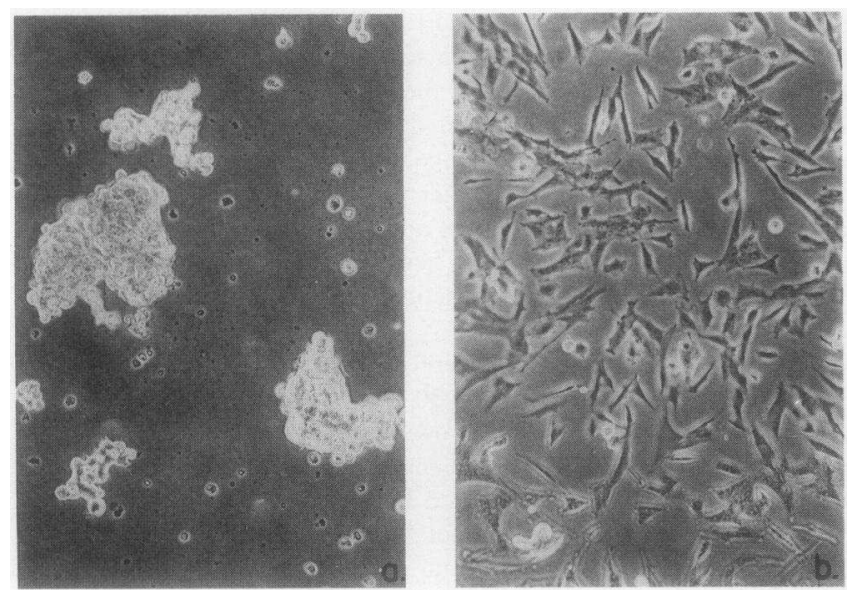

Figure 1. In vitro appearance of adherent and floating sublines of SCLC cell line NCI-H446: $(a)$ floating; $(b)$ surface adherent. the three lines included four no. 1 and four no. 7 chromosomes. There were no significant or consistent structural abnormalities observed in distinguishing among the floating, surface-adherent, or parental sublines of $\mathrm{H} 446$.

Reactivity of SCLC cluster antigens. Flow cytometric analysis was performed using antibodies reactive with dominant SCLC surface antigens. Antibody UJ13A reacts with a 145,000-mol wt protein, found on SCLC and other neuroendocrine tumors but not NSCLC cells (16). This protein has been recently identified on SCLC cells as the sialoglycoprotein NCAM (6). The expression of this antigen was significantly greater in the floating subline than in the adherent subline (Table I) with $P<0.025$. Very marked differences in reactivity were also seen with the AUA1 monoclonal antibody, which reacts with a 40,000-mol wt surface protein of unknown function, found on many epithelial tumors including SCLC (16). The floating aggregate subline of $\mathrm{H} 446$ had three to four times the percentage of positive cells with AUA1 as the surface-adherent subline (Table I). These differences in AUA1 immunoreactivity were significant with $P<0.025$. MAbs SWA 22 and SWA 20, reactive with different surface antigens on SCLC and a variety of neural and epithelial tumors, were equally positive with both surface-adherent and floating sublines of $\mathrm{H} 446$ (17).

$H N K-1$ reactivity. Radioimmunoassays, using the HNK-1 MAb on fixed SCLC cells, consistently demonstrated that the floating $\mathrm{H} 446$ cells had at least five times the reactivity of the surface-adherent subline (Table II). These differences were significant with $P<0.005$. The NSCLC line, H125, used as a control, had the predicted low HNK-1 reactivity. HNK-1 has been demonstrated to react with NCAM and myelin-associated glycoprotein (13). Control antibodies against invariant determinants of HLA and $\beta_{2}$-microglobulin did not discriminate between the adherent and floating sublines of $\mathrm{H} 446$ (Table II) although they demonstrated the previously described paucity of class I histocompatibility antigens in SCLC cells relative to NSCLC cells (29).

To establish that the difference in surface antigen expression of NCAM-related determinants was related to the adherent phenotype, rather than simple clonal selection, we independently reselected surface-adherent and floating sublines from the parent $\mathrm{H} 446$ line. Multiple relatively pure cultures of floating and monolayer $\mathrm{H} 446$ cells were derived, without cloning, over a period of $3 \mathrm{mo}$. Repeat flow cytometric analy-

Table I. Effect of Surface-adherent or Floating Phenotype on Expression of SCLC Surface Antigens

\begin{tabular}{lrr}
\hline & \multicolumn{2}{c}{ Percentage of positive cells } \\
\cline { 2 - 3 } MAb & H446 floaters & H446 adherent \\
\hline UJ13A & $20.0 \pm 1.1$ & $3.6 \pm 0.4$ \\
AUA1 & $37.9 \pm 1.3$ & $12.6 \pm 0.8$ \\
SWA 20 & $53.3 \pm 5.1$ & $46.2 \pm 1.6$ \\
SWA 22 & $67.2 \pm 1.9$ & $62.6 \pm 3.9$ \\
RPC5 & $1.8 \pm 0.6$ & $5.4 \pm 0.3$ \\
\hline
\end{tabular}

Flow cytometric analysis of surface antigen expression on surface-adherent or floating sublines of $\mathrm{H} 446$. The percentage of positive cells represents the mean \pm SEM of duplicate cultures with 25,000 cells analyzed from each sample. RPC5 is an IgG2A murine myeloma protein used in all assays as a negative control. 
Table II. Binding of MAbs to HNK-1, HLA-A,B,C, and $\beta_{2}$-Microglobulin Antigens as Determined by Solid-Phase Radioimmunoassay

\begin{tabular}{lcccc}
\hline \multicolumn{1}{c}{ Cell line } & \multicolumn{3}{c}{ Antibody binding } \\
\cline { 2 - 5 } & NCAM MAb* & Anti-HLA MAb & Anti- $\beta_{2}$-microglobulin MAb & ${\text { Anti- } \beta_{2} \text {-microglobulin sera" }}^{*}$ \\
H446-floaters & $6,459 \pm 316$ & & $c^{125}$ I-protein $A / 10^{5}$ cells & \\
H446-adherent & $1,286 \pm 87$ & $227 \pm 46$ & $217 \pm 42$ & $809 \pm 118$ \\
H125 (NSCLC) & $558 \pm 35$ & $163 \pm 39$ & $246 \pm 35$ & $691 \pm 74$ \\
& & $3,163 \pm 320$ & $3,168 \pm 397$ & $4,469 \pm 347$
\end{tabular}

Solid-phase radioimmunoassay determination of radiobinding of antibodies to the surface-adherent and floating sublines of $\mathrm{H} 446$ and to the NSCLC line H125. Results are the mean of triplicate determinations \pm SEM. All antibody tests used a rabbit anti-mouse Ig connecting antibody followed by incubation with $40,000 \mathrm{cpm} / 25 \mu \mathrm{l}$ of ${ }^{125} \mathrm{I}$-staphylococcal protein A. ${ }^{*}$ Antibody HNK-1 reacts with the Leu 7 determinant on NCAM. ${ }^{\ddagger}$ The W6/32 MAb reacts against an invariant determinant of the HLA-A,B,C heavy chain. ${ }^{\S}$ Antibody BBM.1 reacts against $\beta_{2}$-microglobulin. "A rabbit anti-human $\beta_{2}$-microglobulin hyperimmune serum was also used. The experiment was performed three times with similar results.

sis, with UJ13A and HNK-1 antibodies, confirmed that the surface-adherent sublines were almost entirely nonreactive, while the floating sublines had $25-30 \%$ positive cells for UJ13A and 55-62\% positive cells with HNK-1 (data not shown). Each of these differences were highly significant with $P<0.005$.

We examined two other SCLC cell lines, which grow in vitro as a strongly adherent monolayer, to further investigate the link between low NCAM immunoreactivity and surfaceadherent growth. Such SCLC lines, always of the variant subtype, are unusual but well described in the literature $(1,3)$. The two surface-adherent SCLC lines, H196-B and H1607, were nonreactive with either UJ13A or HNK-1, as was the surfaceadherent NSCLC line H157 (Table III). The classic SCLC lines H209 and H146, and the SCLC-v line N417, each of which forms floating aggregates in culture, were positive for each antibody (Table III). The differences in both UJ13A and HNK-1 immunoreactivity between the three floating aggregate cell lines and the three lines forming monolayer surfaceadherent cultures were highly significant, with $P<0.005$ for each antibody.

Table III. Effect of Adherent or Floating Phenotype on Expression of NCAM Determinants

\begin{tabular}{lrr}
\hline \multirow{2}{*}{\multicolumn{1}{c}{ Cell line }} & \multicolumn{2}{c}{ Percentage of positive cells } \\
\cline { 2 - 3 } & UJ13A & HNK-1 \\
\hline H209 (classic SCLC) & $16.3 \pm 1.6$ & $47.9 \pm 2.3$ \\
H146 (classic SCLC) & $35.2 \pm 0.7$ & $54.1 \pm 2.2$ \\
N417 (variant SCLC) & $27.6 \pm 1.1$ & $68.6 \pm 2.1$ \\
H196-B (adherent SCLC) & $5.5 \pm 0.2$ & $1.0 \pm 0.2$ \\
H1607 (adherent SCLC) & $0.6 \pm 0.1$ & $0.7 \pm 0.1$ \\
H157 (NSCLC) & $0.2 \pm 0.1$ & $8.4 \pm 0.5$ \\
\hline
\end{tabular}

Flow cytometric analysis of NCAM determinants on lung cancer cell lines. The percentage of positive cells represents the mean \pm SEM of quadruplicate cultures with 25,000 cells analyzed from each sample. A 1:500 dilution of UJ13A and a 1:1,000 dilution of HNK-1 were used. MOPC 21, a control mouse IgG1 myeloma protein used as a negative control at a 1:500 dilution, had $<0.6 \%$ positive cells for each cell line. The experiment was repeated twice with similar results.
Keratin analysis. No significant differences were seen between surface-adherent and floating H446 cells in the pattern of intermediate filament immunostaining (Fig. 2). Both sublines showed a pattern of reactivity typical of variant SCLC cells $(25,30)$. The immunoblot results of floating and surfaceadherent $\mathrm{H} 446$ cells were identical with respect to the known keratin molecular weight species between 40,000 and 68,000. Some minor lower molecular weight bands in the surface-adherent subline were noted, which may or may not represent some proteolysis of the keratins.

Analysis of c-myc expression. RNA extracted from the parent $\mathrm{H} 446$ line as well as the surface-adherent and floating sublines was analyzed by Northern blotting and hybridization with a labeled c-myc probe. The parent $\mathrm{H} 446$ cells had the expected high expression of c-myc, as did cells from the surface-adherent and floating sublines, neither of which varied

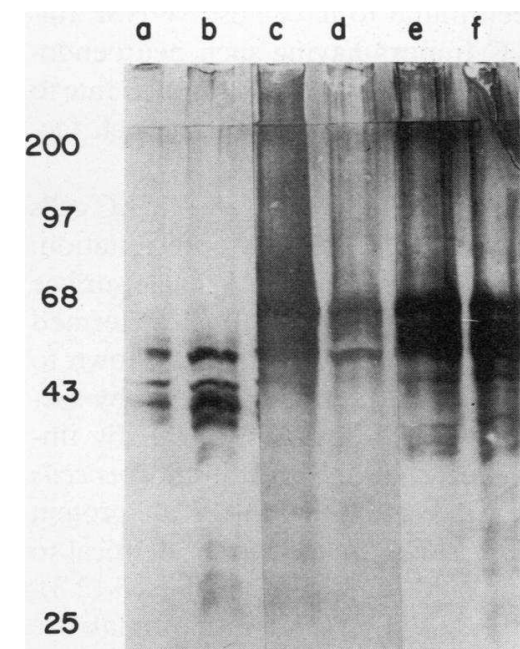

Figure 2. Immunoblots of three cytokeratin antibodies on cytoskeletal preparations from surface-adherent and floating sublines of the variant SCLC cell line NCI-H446. MAb AE-1 is reactive with most acidic keratin species. $\mathrm{MAb}$ AE- 2 is reactive with 56,000- and 65,000-mol wt keratin species. MAb AE-3 is reactive with all eight basic keratins. (a) AE-1 immunoblotting of floating $\mathrm{H} 446$ cells; $(b)$ AE-1 immunoblotting of surface-adherent H446 cells; (c) AE-2 immunoblotting of floating $\mathrm{H} 446$ cells; $(d)$

AE-2 immunoblotting of surface-adherent $\mathrm{H} 446$ cells; $(e)$ AE-3 immunoblotting of floating $\mathrm{H} 446$ cells; $(f)$ AE-3 immunoblotting of surface-adherent $\mathrm{H} 446$ cells. Molecular weight markers shown at left are in thousands. 


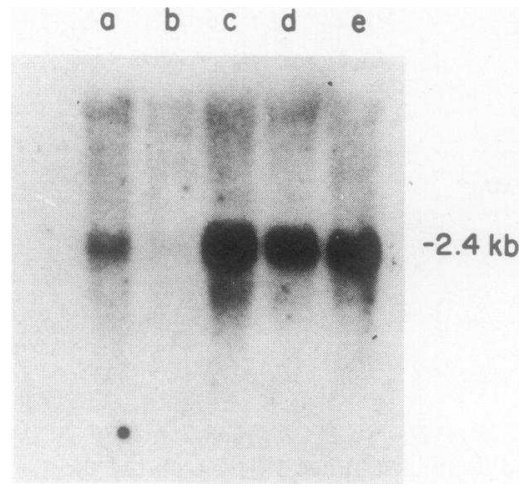

Figure 3. Northern blot analysis of c-myc expression of SCLC and NSCLC cell lines. Lane $a$, SCLC-v line NCI-H82; lane $b$, NSCLC line NCI-H125; lane $c$, the parent NCI-H446 line; lane $d$, the floating subline of NCI-H446; and lane $e$, the surface-adherent subline of NCI-H446.

significantly from the c-myc expression of the parent line (Fig. 3).

\section{Discussion}

One of the most obvious differences between SCLC and NSCLC cells in culture is that NSCLC cells typically grow as anchorage-dependent monolayers in vitro, whereas SCLC cells form multicellular floating spheroidal aggregates. The molecular differences in cell-cell aggregation and substrate adhesion between SCLC and NSCLC responsible for these differences have not been established. The unique SCLC line NCI-H446 provides an opportunity to compare phenotypes of adherent and floating lung cancer cells from a single genotype. The cytogenetic analysis strongly supports the identity of these sublines as SCLC and virtually eliminates the possibility that the adherent $\mathrm{H} 446$ cells might have resulted from contamination by foreign cells. The $\mathrm{H} 446$ subline that grew in an surface-adherent monolayer, similar to that of NSCLC, had a diminution of several neuroendocrine properties seen in SCLC cells. The expression of NSE in surface-adherent $\mathrm{H} 446$ cells is less than in the floating $\mathrm{H} 446$ cells, although not as low as the levels found in most NSCLC cells. A fraction of NSCLC tumors, however, have been found to have positive NSE immunostaining, and NSCLC tumors having such neuroendocrine features have been noted to have a higher response rate to combination chemotherapy than tumors without such factors (31).

Numerous MAbs reactive with SCLC but not NSCLC cells have been found by tissue distribution, immunoprecipitation, and competitive binding studies to react with a single surface protein of $145,000 \mathrm{~mol}$ wt (16). These antibodies, termed SC-1, include MAb UJ13A. SC-1 MAbs have been shown to recognize a SCLC protein identical to one recognized by specific polyclonal antiserum directed against NCAM, by immunoinhibition, immunoprecipitation, and Staphylococcus aureus V8 digestion studies, indicating that the SCLC protein bearing SC-1 determinants is closely related to or identical to NCAM (6). Long polysialic acid units composed of $\alpha-(2,8)$ linked $N$-acetylneuraminic acid units, which in mammals are found exclusively on NCAM, were present on SC-1 antigens in SCLC and neuroblastoma (6). This provides further evidence that SC-1 MAbs recognize NCAM. Our current results demonstrate that binding of the SC-1 MAb UJ13A is significantly decreased in the $\mathrm{H} 446$ subline growing as a monolayer compared with the subline growing as typical floating SCLC spheroids. These floating spheroids demonstrate strong homophilic cell-cell adhesion that may be mediated by NCAM.
SCLC cell lines and biopsies have been shown immunocytochemically to express an antigen recognized by HNK-1, a mouse MAb which recognizes a surface antigen on natural killer cells and on NCAM and the myelin-associated glycoprotein $(12,13)$. NSCLC cells have little or no reactivity with the HNK-1 antibody. Recent studies have shown that HNK-1 recognizes a carbohydrate determinate on a variety of neuroectodermal tumors including glioblastomas, astrocytomas, pheochromocytomas, and medullary thyroid carcinomas (32). By Western blotting, HNK-1 recognizes the 180 - and 140-, but not the $120-\mathrm{kD}$ band of NCAM isolated from adult mouse brain by immunoaffinity purification, using another MAb BSP-2 (13). The HNK-1 epitope appears to be a carbohydrate moiety, in that it is heat resistant, destroyed by periodate treatment, but resistant to pronase (13). Immunoblot data on SCLC cells identify two groups of HNK-1-reactive plasma membrane glycoproteins of 80,000 and 130,000 mol wt (33). SCLC cells also release a $100,000-\mathrm{mol}$ wt glycoprotein reactive with HNK-1 into the spent medium of cultured cells (34). A secreted form of NCAM has also been demonstrated in neural tissues (35).

Our results indicate that HNK-1 is a second NCAM-directed MAb which is markedly less reactive with the surfaceadherent $\mathrm{H} 446$ subline relative to the floating subline. Our finding that the ratio of binding of cells from floating compared to surface-adherent $\mathrm{H} 446$ sublines is approximately 5, with both HNK-1 and UJ13A antibodies, suggests that these two antibodies recognize the same antigen on SCLC cells.

We have shown that two other unusual SCLC-v cell lines, which grow as surface-adherent cell lines and have low expression of neuroendocrine markers, do not react with UJ13A or HNK-1. These findings generalize the association of NCAM immunoreactivity with SCLC growth as floating aggregates. In addition, up to $12 \%$ of NSCLC cancers have features of neuroendocrine differentiation (31). Cell lines established from these tumors are unusual for NSCLC in that the cells grow as floating aggregates and have been demonstrated to react with HNK-1 and another NCAM-directed MAb NKH1 (36). This observation further strengthens the association of NCAM immunoreactivity and the adhesive properties of lung cancer cells and suggests that NCAM expression closely correlates with other markers of neuroendocrine differentiation.

The greater UJ13A and HNK-1 reactivity of floating H446 cells, compared to the $\mathrm{H} 446$ adherent cells is the first reported association between NCAM-related determinants and homophilic cell-cell adhesion between SCLC cells. The association is strengthened by other findings we have reported with SCLC-v cells incubated with retinoic acid (37). These retinoid-treated cells have a marked phenotypic change with the loosely aggregated variant cells becoming much more tightly clustered spheroids. This increased cell-cell adhesion is associated with a marked increase in HNK-1 reactivity among the retinoid-treated cells compared with untreated control cells (37).

Other factors beside the total amount of NCAM protein may be responsible for the different adhesive properties of the floating and adherent H446 cells. Polysialylation of NCAM has been demonstrated to markedly reduce the homophilic binding of neural cells (38). Different NCAM isoforms, owing to alternative RNA splicing, could also potentially change the adhesive properties of the molecule (39). We are currently investigating whether there are differences in sialylation of 
NCAM proteins between the $\mathrm{H} 446$ sublines. In addition, the SCLC lines that grow as adherent monolayers may have an altered interaction with laminin, fibronectin, or other basement membrane proteins, relative to the more common SCLC lines that grow as floating aggregates in vitro. SCLC cells have laminin receptors and bind to laminin in adherence assays (40). However, the inability of most SCLC cells to form monolayer cultures may be related to their lack of detectable fibronectin receptors, and weak binding to fibronectin in vitro (41).

Recent evidence, including keratin patterns, suggest that SCLC derives from an epithelial bronchial cell rather than from cells which have migrated from the neural crest (42). Our finding that the adherent $\mathrm{H} 446$ cells retain a SCLC-v keratin pattern suggests that there is no increase in terminal differentiation in an epithelial direction of these surface-adherent cells despite the morphologic changes. It appears, instead, that the adherent $\mathrm{H} 446$ have not undergone the neuroendocrine differentiation characteristic of most SCLC cells. Neuroendocrine differentiation of bronchial cells in SCLC could explain the appearance of the surface adhesion molecule NCAM. There is evidence that NCAM is a functionally important molecule in cell-cell interactions and adhesion in the developing nervous system (43). NCAM may potentially be important in the early metastasis characteristic of SCLC cells. It has already been demonstrated, for example, that the $20 \%$ of patients with NSCLC whose tumors were positive for NCAM had a signifcantly shorter survival than did NSCLC patients with tumors negative for NCAM immunoreactivity (7). The adherent and floating sublines of $\mathrm{H} 446$, which we have developed, should be useful models to study the expression and modulation of NCAM in SCLC cells.

\section{Acknowledgments}

We would like to thank Dr. A. Gazdar and Mr. E. Russell for the H446, H1607, and H196-B cell lines. We would also like to thank Drs. R. Stahel, R. Souhami, R. Waibel, T. Sun, R. McGarry, and D. Kardamakis for gifts of antibodies.

This study was supported by grant K08 CA 0167 to Dr. Doyle from the National Institutes of Health and a Rizer Memorial Research Grant to Dr. Doyle from the American Cancer Society, Maryland Division. Dr. Elias is a recipient of an American Cancer Society Physician's Research Training Fellowship.

\section{References}

1. Pettingill, O. S., G. D. Sorenson, D. H. Wurster-Hill, T. J. Curphey, W. W. Noll, C. C. Cate, and L. H. Maurer. 1980. Isolation and growth characteristics of continuous cell lines from small-cell carcinoma of the lung. Cancer. 45:906-918.

2. Gazdar, A. F., D. N. Carney, M. Nau, and J. D. Minna. 1985. Characterization of variant subclasses of cell lines derived from small cell lung cancer having distinctive biochemical, morphological and growth properties. Cancer Res. 45:2924-2930.

3. Carney, D. N., A. F. Gazdar, G. Bepler, J. C. Guccion, P. J. Marangos, T. W. Moody, M. H. Zweig, and J. D. Minna. 1985. Establishment and identification of small cell lung cancer cell lines having classic and variant features. Cancer Res. 45:2913-2923.

4. Marangos, P. J., A. F. Gazdar, and D. N. Carney. 1982. Neuron specific enolase in human small cell carcinoma cultures. Cancer Lett. 15:67-71.

5. Gazdar, A. F., M. H. Zweig, D. N. Carney, A. C. Van Steirteghen, S. B. Baylin, and J. D. Minna. 1981. Levels of creatine kinase and its BB isoenzyme in lung cancer specimens and cultures. Cancer Res. 41:2773-2777.
6. Moolenaar, C. E. C., E. J. Mueller, D. J. Schol, C. G. Figdor, E. Bock, D. Bitter-Suermann, and R. J. A. M. Michalides. 1990. Expression of an NCAM related sialoglycoprotein in small cell lung cancer and neuroblastoma. Cancer Res. 50:1102-1106.

7. Kibbelaar, R. E., C. E. C. Moolenaar, R. J. A. M. Michalides, D. Bitter-Suermann, B. J. Addis, and W. J. Mooi. 1989. Expression of the embryonal neural cell adhesion molecule N-CAM in lung carcinoma: diagnostic usefulness of monoclonal antibody 735 for the distinction between small cell lung cancer and non-small cell lung cancer. $J$. Pathol. 159:23-28.

8. Baylin, S. B., M. D. Abeloff, G. Goodwin, D. N. Carney, and A. F. Gazdar. 1980. Activities of L-dopa decarboxylase and diamine oxidase (histaminase) in human lung cancers and decarboxylase as a marker for small (oat) cell cancer in cell culture. Cancer Res. 40:1990-1994.

9. Cuttitta, F., S. Rosen, A. F. Gazdar, and J. D. Minna. 1980. Monoclonal antibodies that demonstrate specificity for several types of human lung cancer. Proc. Natl. Acad. Sci. USA. 78:4591-4595.

10. Simms, E., A. F. Gazdar, P. G. Abrams, and J. D. Minna. 1980. Growth of human small cell (oat cell) carcinoma of the lung in serumfree growth factor-supplemented medium. Cancer Res. 40:4356-4363.

11. Carney, D. N., A. F. Gazdar, and J. D. Minna. 1980. Positive correlation between histological tumor involvement and generation of tumor cell colonies in agarose in specimens taken directly from patients with small-cell carcinoma of the lung. Cancer Res. 40:1820 1823.

12. Bunn, P. A., Jr., I. Linnoila, J. D. Minna, D. Carney, and A. F. Gazdar. 1985. Small cell lung cancer, endocrine cells of the fetal bronchus, and other neuroendocrine cells express the Leu-7 antigenic determinant present on natural killer cells. Blood. 65:764-768.

13. Kruse, J., R. Mailhammer, H. Wernecke, A. Faissner, I. Sommer, C. Goridis, and M. Schachner. 1984. Neural cell adhesion molecules and myelin-associated glycoprotein share a common carbohydrate moiety recognized by monoclonal antibodies L2 and HNK-1. Nature (Lond.). 311:153-155.

14. Barnstable, C. J., W. F. Bodmer, G. Brown, G. Galfre, C. Milstein, A. F. Williams, and A. Ziegler. 1978. Production of monoclonal antibodies to group A erythrocytes, HLA and other human cell surface antigens: new tools for genetic analysis. Cell. 14:9-18.

15. Tseng, S. C. G., M. J. Jarvinen, W. G. Nelson, J. W. Huang, J. Woodcork-Mitchell, and T. T. Sun. 1982. Correlation of specific keratins with different types of epithelial differentiation: monoclonal antibody studies. Cell. 30:361-372.

16. Souhami, R. L., P. C. L. Beverly, and L. G. Bobrow. 1987. Antigens of small-cell lung cancer. Lancet. 8554:325-326.

17. Strnad, J., A. E. Hamilton, L. S. Beavers, G. C. Gamboa, L. D. Apelgren, L. D. Taber, J. R. Sportsman, T. F. Bumol, J. D. Sharp, and R. A. Gadski. 1989. Molecular cloning and characterization of a human adenocarcinoma/epithelial cell surface antigen complementary DNA. Cancer Res. 49:314-317.

18. Waibel, R., C. J. O'Hara, A. Smith, and R. A. Stahel. 1988. Tumor-associated membrane sialoglycoprotein on human small cell lung carcinoma identified by the IgG2a monoclonal antibody SWA20. Cancer Res. 48:4318-4323.

19. Cox, R. A. 1968. The use of guanidinium chloride in the isolation of nucleic acid. Methods Enzymol. 128:120-129.

20. Lehrach, H., D. Diamond, J. M. Wozney, and H. Boedtker. 1977. RNA molecular weight determinations by gel electrophoresis under denaturing conditions, a critical re-examination. Biochemistry. 16:4743-4749.

21. Dalla-Favera, R., S. Martinotti, R. C. Gallo, J. Erickson, and C. M. Croce. 1983. Translocation and rearrangements of the c-myc oncogene locus in human undifferentiated B cell lymphomas. Science (Wash. DC). 219:963-967.

22. Taub, R., I. Kirsch, C. Morton, G. Lenior, D. Swan, S. Tronnick, S. Aaronson, and P. Leder. 1982. Translocation of the c-myc gene into the immunoglobulin heavy chain locus in human Burkitt lymphoma and murine plasmacytoma cells. Proc. Natl. Acad. Sci. USA. 79:7837-7842. 
23. Feinberg, A. P., and B. Vogelstein. 1981. A technique for radiolabeling DNA restriction endonuclease fragments to high specific activity. Anal. Biochem. 132:6-13.

24. Wu, Y. G., and J. G. Rheinwald. 1981. A new small (40 kD) keratin filament made by some cultured human squamous cell carcinomas. Cell. 25:627-631.

25. Elias, A. D., B. F. Cohen, and S. D. Bernal. 1988. Keratin subtypes of small cell lung cancer. Cancer Res. 48:2724-2729.

26. Testa, J. R., S. Misawa, N. Oguma, K. Van Sloten, and P. H. Wiernik. 1985. Chromosomal alterations in acute leukemia patients studied with improved culture methods. Cancer Res. 45:430-434.

27. Lowry, O. H., N. J. Rosebrough, A. L. Farr, and R. J. Randall. 1951. Protein measurement with the Folin phenol reagent. J. Biol. Chem. 193:265-275.

28. Whang-Peng, J., C. S. Kao-Shan, E. C. Lee, P. A. Bunn, D. N. Carney, A. F. Gazdar, and J. D. Minna. 1982. Specific chromosome defect associated with human small-cell lung cancer deletion $3 p$ (14-23). Science (Wash. DC). 215:181-182.

29. Doyle, A., W. J. Martin, K. Funa, R. Gazdar, D. Carney, S. E. Martin, I. Linnoila, F. Cuttitta, J. Mulshine, P. Bunn, et al. 1985. Markedly decreased expression of class I histocompatibility antigens, protein, and mRNA in human small-cell lung cancer. J. Exp. Med. 161:1135-1151.

30. Broers, J. L. V., D. N. Carney, L. de Ley, G. P. Vooijs, and F. C. S. Ramaekers. 1985. Differential expression of intermediate filament proteins distinguishes classic from variant small-cell lung cancer cell lines. Proc. Natl. Acad. Sci. USA. 82:4409-4413.

31. Graziano, S. L., R. Mazid, N. Newman, A. Tatum, A. Oler, J. A. Mortimer, J. J. Gullo, S. M. DiFino, and A. J. Scalzo. 1989. The use of immunoperoxidase markers to predict chemotherapy response in patients with non-small cell lung cancer. J. Clin. Oncol. 7:13981406.

32. Seeger, R. C., H. M. Rosenblatt, K. Imai, and S. Ferrone. 1981. Common antigenic determinants on human melanoma, glioma, neuroblastoma and sarcoma cells. Cancer Res. 41:2714-2717.

33. Willison, H. J., J. D. Minna, R. O. Brady, and R. Quarles. 1986. Glycoconjugates in nervous tissue and small cell lung cancer share immunologically cross-reactive carbohydrate determinants. J. Neuroimmunol. 10:353-365.

34. Noronha, A. B., J. R. Harper, A. A. Ilyas, R. A. Reisfeld, and R. H. Quarles. 1986. Myelin-associated glycoprotein shares an antigenic determinant with a glycoprotein of human melanoma cells. $J$. Neurochem. 47:1558-1565.

35. Gower, H. J., C. H. Barton, V. L. Elson, J. Thompson, S. E. Moore, G. Dickson, and F. S. Walsh. 1988. Alternative splicing generates a secreted form of N-CAM in muscle and brain. Cell. 55:995-968.

36. Gazdar, A. F., R. I. Linnoila, P. Jewett, A. M. Koros, and K. H. Kortright. 1987. Natural killer cell associated antigen NKH-1 is a marker for neuroendocrine tumors of the lung. Proc. Am. Assoc. Cancer Res. 28:359. (Abstr.)

37. Doyle, L. A., D. Giangiulio, A. Hussain, H.-J. Park, R.-W. C. Yen, and M. Borges. Differentiation of variant small cell lung cancer to a classic morphology by retinoic acid. Cancer Res. 49:6745-6751.

38. Hoffman, S., and G. M. Edelman. 1983. Kinetics of homophilic binding of embryonic and adult forms of the neural cell adhesion molecule. Proc. Natl. Acad. Sci. USA. 80:5762-5766.

39. Cunningham, B. A., J. J. Hemperly, B. A. Murray, E. A. Prediger, R. Brackenbury, and G. M. Edelman. 1983. Neural cell adhesion molecule: structure, immunoglobulin-like domains, cell surface modulation, and alternative RNA splicing. Science (Wash. DC). 236:799806.

40. Tagliabue, E., S. Menard, R. Pellegrini, and M. I. Colnaghi. 1990. Laminin receptors on small cell lung cancer cells. In The Second International Workshop on Small Cell Lung Cancer Antigens, London, UK, April 1990. (Abstr.)

41. Luk, G. D., and S. B. Baylin. 1986. Anchorage dependency effects on difluoromethylornithine cytotoxicity in human lung cancer cells. Cancer Res. 46:1844-1848.

42. Gazdar, A. F., and D. N. Carney. 1984. Endocrine properties of small cell lung cancer. In The Endocrine Lung in Health and Disease. K. L. Becker and A. F. Gazdar, editors. W. B. Saunders Co., Philadelphia, PA. 501-508.

43. Edelman, G. M. 1983. Cell adhesion molecules. Science (Wash. DC). 219:450-457. 